\title{
Physical and thermal properties of a chitosan/alginate nanolayered PET film
}

\author{
Maria G. Carneiro-da-Cunha ${ }^{a}$, Miguel A. Cerqueira ${ }^{b}$, Bartolomeu W.S. Souza ${ }^{b}$, \\ Sandra Carvalhoc ${ }^{c}$, Mafalda A.C. Quintas ${ }^{b, d}$, José A. Teixeira ${ }^{b}$, António A. Vicente ${ }^{\mathrm{b}, *}$ \\ a Departamento de Bioquímica/Laboratório de Imunopatologia Keizo Asami, Universidade Federal de Pernambuco, Campus Universitário, \\ $s / n$, Cidade Universitária, CEP 50.670-420 Recife, PE, Brazil \\ ${ }^{\mathrm{b}}$ IBB - Institute for Biotechnology and Bioengineering, Centre of Biological Engineering, Universidade do Minho, Campus de Gualtar, $4710-057$ Braga, Portugal

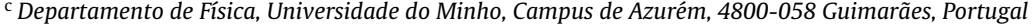 \\ d CBQF/Escola Superior de Biotecnologia, Rua Dr Antonio Bernardino de Almeida, 4200-072 Porto, Portugal
}

\section{A R T I C L E I N F O}

\section{Article history:}

Received 16 November 2009

Received in revised form 12 February 2010

Accepted 20 April 2010

Available online 29 April 2010

\section{Keywords:}

PET

Layer-by-layer

Chitosan

Alginate

Physical and thermal properties

\begin{abstract}
A B S T R A C T
Nanolaminates have been reported to have applications in different areas, such as the preparation of multilayer films, coating biomedical appliances or multilayer edible coatings with enhanced properties for applications in the food industry. This work aims at characterizing the surface properties, water vapor permeability, and thermal and mechanical properties of a nanolayered film. The film was produced using two polysaccharides with opposite charges, chitosan and sodium alginate deposited on to aminolyzed/charged PET. Contact angle measurements showed differences in the films with a successively higher number of layers. SEM images allowed the measurement of the thickness of the layers. The nanolayered film had a water vapor permeability of $(0.85 \pm 0.04) \times 10^{-11} \mathrm{~g} \mathrm{~m}^{-1} \mathrm{~s}^{-1} \mathrm{~Pa}^{-1}$ and a hardness increase of $0.245 \pm 0.06 \mathrm{GPa}$. DSC and TG analyses of the nanolayered film showed increases of $39.2 \%$ in the melting energy when compared with the PET film used as support, and a decrease in the decomposition temperature from 386 to $331^{\circ} \mathrm{C}$.
\end{abstract}

(c) 2010 Elsevier Ltd. All rights reserved.

\section{Introduction}

In recent years, many studies have shown that films and/or coatings of different polysaccharides have promising applications in the biomedical (Kujawa, Schmauch, Viitala, Badia, \& Winnik, 2007; Zhong, Li, \& Haynie, 2006) and food fields (Cerqueira et al., 2009; Ribeiro, Vicente, Teixeira, \& Miranda, 2007). The application of different materials in multilayer films has been shown to be an efficient way of improving transport properties (Jang, Rawson, \& Grunlan, 2008). Recently, literature suggests that these materials can present improved functionality when used on a nanoscale (Weiss, Takhistov, \& McClements, 2006).

A nanolaminate consists of two or more layers of material with nanometer dimension that are physically or chemically bonded to each other. One of the most powerful methods of preparation is the layer-by-layer (LbL) deposition technique, in which the charged surfaces are coated with multiple nanolayers of different materials (Decher \& Schlenoff, 2002). Multilayer films or coatings of nanometer-thickness can be made by successive adsorption of oppositely charged polyelectrolytes on a solid carrier providing potential applications of such films for food preservation and

\footnotetext{
* Corresponding author. Tel.: +351253 604419; fax: +351253678986.

E-mail address: avicente@deb.uminho.pt (A.A. Vicente).
}

coatings for implant devices (Rudra, Dave, \& Hayne, 2006). These materials may constitute either polycations or polyanions, depending on their functional group type. In food, pharmaceutical, and cosmetic industries polysaccharides are often used. This sequential adsorption approach has also been successfully used to manipulate many different types of materials including conducting polymers, light emitting polymers, molecular dyes, fullerenes, precursor polymers, nonlinear optical polymers, biomaterials, and various inorganic systems (Abu-Sharkh, 2006; Dronov et al., 2008; Lukkari et al., 2002; Yoo, Shiratori, \& Rubner, 1998). Another critical use of this approach has been the surface modification of polymeric materials towards the improvement of their cytocompatibility (Zhu, Gao, He, \& Shen, 2004).

Polyethylene terephthalate (PET) has been seen as a good candidate for biomaterial applications due to its excellent physicochemical properties: good mechanical and transport properties, thermal stability and optical transparency (Jang et al., 2008; Lin, Chang, \& Lin, 2008; Qu et al., 2005; Shogren, 1997), and moderate biocompatibility (Fávaro, Rubira, Muniz, \& Radovanovic, 2007; Fu, Ji, Yuan, \& Shen, 2005).

Alginate is a linear binary copolymer that consists of $(1 \rightarrow 4)$ linked $\beta$-D-mannuronic acid and $\alpha$-L-guluronic acid residues. Sodium alginate, $\mathrm{C}_{6} \mathrm{H}_{7} \mathrm{O}_{6} \mathrm{Na}$, is the sodium salt of alginic acid. It is a natural anionic polysaccharide that can be extracted from marine brown algae. Sodium alginate is a good chelator and can be used 
to remove radioactive toxins such as iodine-131 and strontium-90 from the body that have taken the place of their non-radioactive counterparts (Sutton et al., 1971). It is also used in immobilizing enzymes by inclusion and is used as a food thickener and stabilizer and in medicines, paint, and paper coating. Alginate was also been used as a film and coating component. The barrier properties of alginate films suitable for aroma encapsulations have been reported recently (Hambleton, Frédéric Debeaufort, Bonnotte, \& Voilley, 2009; Olivas \& Barbosa-Cánovas, 2008). Their application as coatings for fresh-cut fruits has been shown to increase shelflife (Raybaudi-Massilia, Mosqueda-Melgar, \& Martín-Belloso, 2008; Rojas-Graü, Tapia, \& Martín-Belloso, 2008; Tapia et al., 2008).

Chitosan has valuable properties: it may act as a haemostatic and hypoallergenic agent; together with its natural anti-bacterial properties, it can be of biomedical use in applications such as wound dressings and bandages (Kumar, Muzzarelli, Muzzarelli, Sashiwa, \& Domb, 2004). It is a natural cationic polysaccharide formed by the N-deacetylation of chitin, a product found in crustacean shells. It is a linear binary copolymer that consists of $\beta(1 \rightarrow 4)$-linked 2-acetoamido-2-deoxy- $\beta$-D-glucopyranose (GlcNAc; A-unit) and 2-amino-2-deoxy- $\beta$-D-glucopyranose (GlcN; $D$-unit). Recently, there has been a great interest in edible films and coatings from chitosan, due to their good transport and mechanical properties (Casariego et al., 2009; Souza et al., 2009; Vargas, Albors, Chiralt, \& González-Martínez, 2009).

The aim of this work was to characterize a nanolayered film assembled through layer-by-layer. The film was produced using two polysaccharides with opposite charges, chitosan and sodium alginate, onto aminolyzed/charged PET. The resulting film was characterized in terms of its surface properties, water vapor permeability, and thermal and mechanical properties. Such characterization will assist in developing industrial application for these films.

\section{Materials and methods}

\subsection{Preparation of nanolayered film}

The nanolayered film used in this study was composed of an aminolyzed/charged PET (A/C PET) sustaining layer adsorbed with a polysaccharide multilayer (constituted of 5 polysaccharide layers: Alg-Ch-Alg-Ch-Alg, where Alg stands for alginate and Ch stands for chitosan).

Polyethylene terephthalate (PET) films (Canson, France) were cut into rectangular pieces of $0.8 \mathrm{~cm} \times 5.0 \mathrm{~cm}$ and circular pieces of $5.0 \mathrm{~cm}$ of diameter and were aminolyzed as described by Fu et al. (2005). Briefly, PET films were cleaned in ethanol/water (1:1, v/v) (99.8\%, Riedel-de Haën, Germany) solution for $3 \mathrm{~h}$, followed by a thorough rinsing with distilled water, and dried at $30^{\circ} \mathrm{C}$ for $24 \mathrm{~h}$. Afterwards, the film was immersed in $0.06 \mathrm{~g} \mathrm{~mL}^{-1} 1,6-$ hexanediamine/propanol (Aldrich-Germany and Sigma-AldrichUSA, respectively) solution at $37^{\circ} \mathrm{C}$ for $4 \mathrm{~h}$, thoroughly washed with distilled water to remove free 1,6-hexanediamine, and finally dried at $37^{\circ} \mathrm{C}$ for $24 \mathrm{~h}$. The aminolyzed PET films were treated with $0.1 \mathrm{M}$ $\mathrm{HCl}$ (Merck, Germany) solution for $3 \mathrm{~h}$ at room temperature $\left(20^{\circ} \mathrm{C}\right)$ and then washed with a large amount of distilled water, and dried at $30^{\circ} \mathrm{C}$ for $24 \mathrm{~h}$.

For preparing the polysaccharide layers, a sodium alginate solution was prepared dissolving $0.2 \%(\mathrm{w} / \mathrm{v})$ sodium alginate (Manutex RSX, Kelco International, Ltd., Portugal) in distilled water and a chitosan (90\% deacetylation, Aqua Premier Co. Ltd., Thailand) solution was prepared dissolving $0.2 \%(\mathrm{w} / \mathrm{v})$ chitosan in a $1.0 \%(\mathrm{v} / \mathrm{v})$ lactic acid solution. To achieve full dissolution these solutions were agitated (using a magnetic stirrer) at approximately $200 \mathrm{rpm}$ during $2 \mathrm{~h}$ at room temperature $\left(20^{\circ} \mathrm{C}\right)$. Sodium alginate and chitosan solutions $\mathrm{pH}$ was adjusted to $\mathrm{pH} 7$ with a solution of $1 \mathrm{M}$ sodium hydroxide (Riedel-de Haen, Germany) and pH 3 with a $1 \mathrm{M}$ lactic acid (Merck, Germany) solution, respectively.

In order to prepare the nanolayered film, A/C PET pieces were dipped into the Alg solution for $15 \mathrm{~min}$ and subsequently rinsed with a $\mathrm{pH} 7$ solution (deionized water with $\mathrm{pH}$ adjusted to 7 with a $1 \mathrm{M} \mathrm{NaOH}$ solution). The samples were dried with a flow of nitrogen and the procedure was repeated, this time using $\mathrm{Ch}$ as the polyelectrolyte and rising with a $\mathrm{pH} 3$ buffer solution. This process was repeated with the alternate deposition of a total of 5 layers (Alg-Ch-Alg-Ch-Alg). The obtained nanolayered films (A/C PETAlg-Ch-Alg-Ch-Alg) were then maintained at $20 \pm 2{ }^{\circ} \mathrm{C}$ and $50 \pm 5 \%$ relative humidity $(\mathrm{RH})$ before analysis (as provided by the laboratory air conditioning system).

\subsection{Materials characterization}

\subsubsection{Zeta potential and conductivity}

The zeta potential and conductivity of the polyelectrolyte (Alg and $\mathrm{Ch}$ ) solutions were determined by dynamic light scattering (DLS) (Zetasizer Nano ZS, Malvern Instruments, UK). Each sample was analyzed in a folded capillary cell. Three true replicates were conducted, with three readings for each of them. Results are given as the average \pm standard deviation of the experimental values.

\subsubsection{UV/vis absorbance}

The UV-vis analyses were performed using a UV-vis spectrophotometer (Jasco 560, Germany) and were used to follow the multilayer films construction (Fu et al., 2005). The absorbance was measured at $260 \mathrm{~nm}$ on dried films (Santos et al., 2003; Sionkowska, 2006; Wasikiewicz, Yoshii, Nagasawa, Wach, \& Mitomo, 2005).

\subsubsection{Contact angle analysis}

Contact angle $(\theta)$ of the nanolayered film surface was measured in a face contact angle meter (OCA 20, Dataphysics, Germany) using the sessile drop method (Newman \& Kwok, 1999). A $2 \mu$ L droplet of ultra pure water was placed on the horizontal surface with a $500 \mu \mathrm{L}$ syringe (Hamilton, Switzerland), with a needle ( $0.75 \mathrm{~mm}$ diameter). Measurements were made at 0,15 and $30 \mathrm{~s}$. Ten replicates of contact angle measurements were performed at $20.5 \pm 0.3^{\circ} \mathrm{C}$.

\subsubsection{Thermogravimetric analysis (TGA) and differential scanning calorimetry (DSC)}

TGA (Shimadzu TGA-50, Japan) and DSC (Shimadzu DSC-50) temperature scans of the samples were carried out in $\mathrm{N}_{2}$ atmosphere at $10^{\circ} \mathrm{C} \mathrm{min}^{-1}$ (from room temperature). The samples were weighed (approximately $8-10 \mathrm{mg}$ ) in aluminum DSC pans being the empty pans used as a reference.

\subsubsection{Water vapor permeability (WVP) measurement}

The measurements were performed gravimetrically based on ASTM E96-92 method (Casariego et al., 2009; Guillard, Broyart, Bonazzi, Guilbert, \& Gontard, 2003; McHugh, Avena-Bustillos, \& Krochta, 1993). Two replicates were obtained for each sample.

WVP was determined experimentally for the sustaining layer (A/C PET) and for the obtained nanolayered film (A/C PET-Alg-ChAlg-Ch-Alg). Film thickness was determined by SEM analyses.

The polysaccharide multilayer (Alg-Ch-Alg-Ch-Alg) WVP $\left(\mathrm{WVP}_{B}\right)$ was determined by the following equation (Cooksey, Marsh, \& Doar, 1999):

$\mathrm{WVP}_{B}=\frac{L_{B}}{\left(L_{T} / \mathrm{WVP}_{T}\right)-\left(L_{A} / \mathrm{WVP}_{A}\right)}$

where $A, B$ and $T$ refer, respectively, to: (i) the sustaining layer $(\mathrm{A} / \mathrm{C}$ PET), (ii) the polysaccharide multilayer (Alg-Ch-Alg-Ch-Alg) and (iii) the resulting nanolayered film (A/C PET-Alg-Ch-Alg-Ch-Alg). 
$L$ corresponds to the thickness of the materials in $\mathrm{mm}$ and WVP to the water vapor permeability in $\mathrm{g}(\mathrm{m} \mathrm{sPa})^{-1}$.

\subsubsection{Scanning electron microscopy (SEM) and energy dispersive spectroscopy (EDS) analysis}

The surface morphology of the studied materials was examined using a scanning electron microscope (Nova NanoSEM 200, Netherlands) with an accelerating voltage from 10 to $15 \mathrm{kV}$. The energy dispersive spectroscopy analyses were performed in an integrated system EDS-BSED (EDAX). Before analysis, all samples were mounted on aluminum stubs using carbon adhesive tape and sputter-coated with gold (thickness of about $10 \mathrm{~nm}$ ).

\subsubsection{Nanoindentation experiments}

The hardness $(H)$ was evaluated by depth-sensing indentation, using a MicroMaterials Nanotest (UK) system at maximum load of $0.15 \mathrm{mN}$, at a temperature of $24^{\circ} \mathrm{C}$. Depth-sensing indentation measurements are used to determine the hardness modulus. The hardness $(H)$ was determined by Eq. (2) (Oliver \& Pharr, 1992).

$H=\frac{P}{A}$

where $H$ is expressed in Pa, $P(\mathrm{~N})$ is the maximum applied load and $A\left(\mathrm{~m}^{2}\right)$ is the contact area of the indentation, at the maximum load.

In order to have representative average values for the mechanical properties 25 tests were performed in each sample. In the test, the load is increased in steps until a nominal load of $0.15 \mathrm{mN}$ is reached. Two creep periods of $30 \mathrm{~s}$ were performed during the tests: at maximum load and at the $10 \%$ lowest load during unloading. Correction of the geometrical defects in the tip of the Berkovich indenter, thermal drift of the equipment and uncertainty of the initial contact was also performed in agreement with what was proposed (Antunes, Cavaleiro, Menezes, Simões, \& Fernandes, 2002; Dowling et al., 1997).

\subsection{Statistical procedures}

The statistical analyses of the data were performed using analysis of variance (ANOVA) and linear regression analysis (Excel, 2003).

\section{Results and discussion}

\subsection{Preparation of nanolayered film}

To confirm the PET aminolysis, energy dispersive spectroscopy (EDS) was performed (Fig. 1). Before the PET aminolysis there was no nitrogen peak present (Fig. 1A) and after the aminolysis of PET substrate the expected $\mathrm{N}$ peak (normalized area: $2.72 \%$ ) was detected (Fig. 1B). Moreover, during aminolysis PET acquires carbon and nitrogen atoms and loses oxygen atoms. This phenomenon can be confirmed by the change in the EDS normalized areas: the original PET samples have normalized areas of $68.19 \%$ (for carbon atoms) and $31.81 \%$ (for oxygen atoms) whereas A/C PET, shows normalized areas of 75.85 and $21.43 \%$, respectively.

The confirmation of the electrostatic properties of the alginate and chitosan solutions was performed by determination of their zeta potential; this was done in order to guarantee their correct interaction with the $\mathrm{A} / \mathrm{C}$ PET surface. The opposite charges of these two solutions were confirmed by dynamic light scattering with values of: $-62.13 \pm 4.01 \mathrm{mV}$ for sodium alginate solution and $+58.28 \pm 4.18 \mathrm{mV}$ for chitosan solution, showing that they can interact by electrostatic forces.

The layer deposition was monitored by measuring the increase in absorbance at $260 \mathrm{~nm}$ for multilayer films with up to 5 layers, as shown in Fig. 2. The increase in absorbance due to the layer
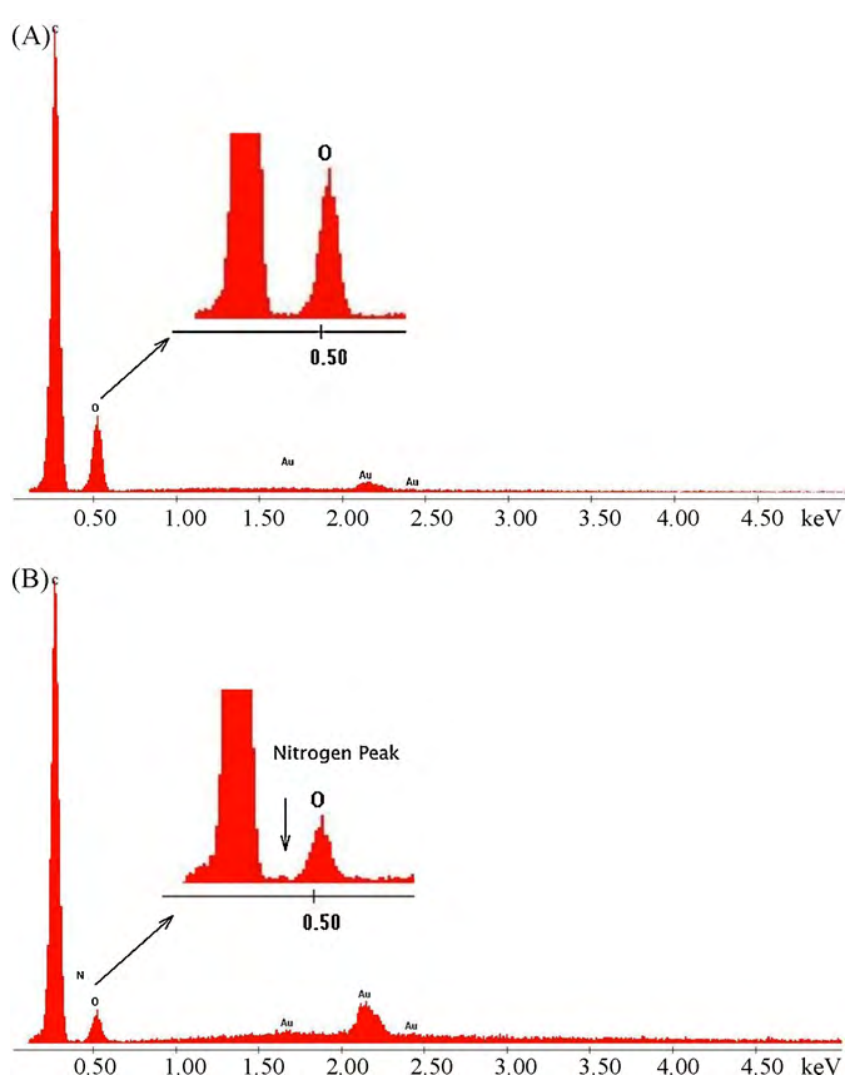

Fig. 1. Energy dispersive spectroscopy (EDS) spectra of original PET (A) and of A/C PET (B). The indication arrow marks the nitrogen peak.

deposition is in agreement with other works where chitosan deposition by LbL was characterized by UV-VIS spectroscopy (Fu et al., 2005; Strand, TØmmeraas, Värum, \& Østgaard, 2001). The value of wavelength used $(260 \mathrm{~nm})$ was chosen after the range used by Wasikiewicz et al. (2005) and Santos et al. (2003), which spanned from 240 to $280 \mathrm{~nm}$.

These results confirm the successful construction of the nanolayered film, which allowed further characterization of this material.

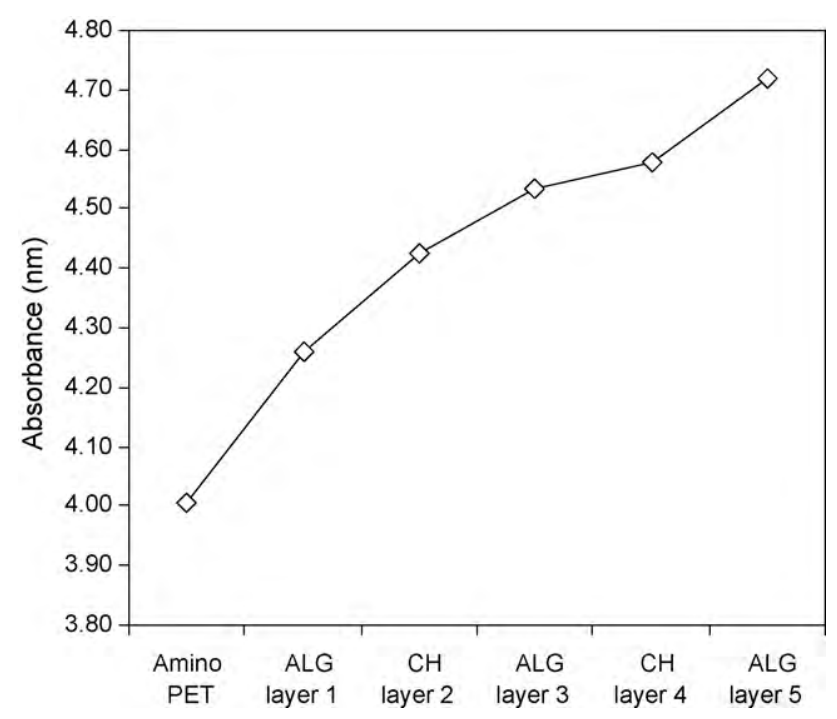

Fig. 2. Multilayer assembly monitored by UV absorbance at $260 \mathrm{~nm}$, to the A/C PET and the successive adsorption of alginate/chitosan layers. 
Table 1

Values of water vapor permeability (WVP) for A/C PET, polysaccharide multilayer, nanolayered film and film thickness (determined by SEM),

\begin{tabular}{|c|c|c|c|c|c|}
\hline \multirow[t]{2}{*}{ Sample } & \multirow[t]{2}{*}{ Thickness $(\mu \mathrm{m})$} & \multirow[t]{2}{*}{ WVP $\left(\mathrm{g} \mathrm{m}^{-1} \mathrm{~s}^{-1} \mathrm{~Pa}^{-1}\right)$} & \multicolumn{3}{|l|}{ Regression results } \\
\hline & & & 95\% Lower confidence limit & 95\% Upper confidence limit & $R^{2}$ \\
\hline $\mathrm{A} / \mathrm{C}$ PET & 100.10 & $8.168 \times 10^{-12 a}$ & $8.537 \times 10^{-12}$ & $7.800 \times 10^{-12}$ & 0.997 \\
\hline Nanolayered film & 100.22 & $7.358 \times 10^{-12 a}$ & $7.794 \times 10^{-12}$ & $6.923 \times 10^{-12}$ & 0.995 \\
\hline Polysaccharide multilayer & 0.12 & $8.881 \times 10^{-14 b}$ & & Not applicable & \\
\hline
\end{tabular}

a Estimated using regression analysis.

b Calculated using Eq. (1).

\subsection{Nanolayered film characterization}

\subsubsection{Contact angle measurements}

Contact angle values observed in PET, A/C PET and when successive layers of alginate and chitosan were added can be observed in Fig. 3. When considering the time of observation (after drop application), it can be concluded that it does not affect the global tendencies. Tukey test $(\alpha=3 \%)$ showed that for layers Ch2 to Alg5, the time of measurement did not significantly affect the value of contact angle. For PET, A/C PET and Alg1 layers, contact angle significantly decreased from 0 to $15 \mathrm{~s}$. After $15 \mathrm{~s}$, no significant differences were found.

The contact angle measured with $30 \mathrm{~s}$ on the original PET film was found to be $81.78 \pm 2.18\left(^{\circ}\right)$ and after the aminolyzation of PET, the value decreased to $73.56 \pm 1.31\left(^{\circ}\right)$. These decrease in contact angle after PET aminolyzation has been previously reported in the literature (Xu, Wang, Fan, Ji, \& Shen, 2008). A significant decrease in contact angle after aminolyzation was also found when comparing polyurethane substrate before and after aminolyzation (Zhu et al., 2004).

As for the effect of layer deposition on A/C PET, the change of the contact angle values shows the progressive construction of the film by alternate deposition of the nanolayers (Fig. 3). Typically, the alginate layer induced an increase of contact angle whereas chitosan layer deposition led to a contact angle decrease.

The contact angle measurement is a useful tool to determine the hydrophobic or hydrophilic characteristics of a surface. The most wettable surfaces present low values $\left(\theta<20^{\circ}\right)$ and the hydrophobic surfaces, on the contrary, show high values $\left(\theta>70^{\circ}\right)$ of the contact angle. The wettability of a surface depends on the nature of the outermost layer and not on the initial substrate film; however, the

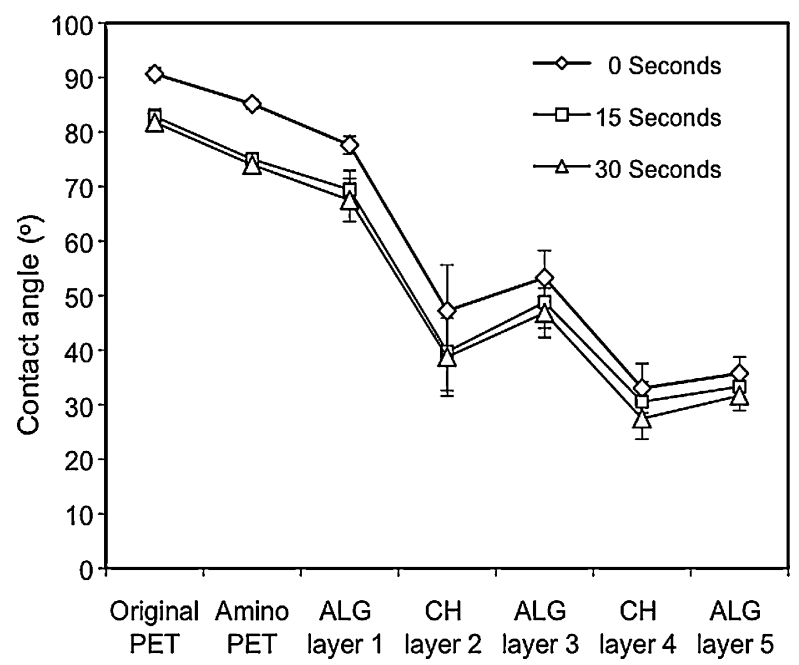

Fig. 3. The contact angle measured on original PET, A/C PET and on the five successive layers (measured 0,15 and $30 \mathrm{~s}$ after drop application). Each data point is an average of 10 determinations and the error bars represent the standard deviation. interpenetration of layers may cause some influence on that property (Fu et al., 2005), especially at the nanoscale. Moreover, changes in $\mathrm{pH}$ can significantly affect wettability of a surface, since they can change the film structure itself. For example, at higher $\mathrm{pH}$ values the assembled chains of chitosan are more weakly charged and adopt a loopier and globular conformation than those at lower $\mathrm{pH}$ values; at $\mathrm{pH} 2.9$, those chains present a smoother surface, adopting more flat structures thus leading to a thinner chitosan layer (Fu et al., 2005; Yoo et al., 1998). The conjugation of variables such as the degree of aminolyzation, number of layers, $\mathrm{pH}$ of each layer and the polymer present in each layer will then be crucial for layer binding and therefore will affect film wettability. This may explain the fact that the observed tendency (contact angles with higher values for alginate layers and lower values for chitosan layers) is apparently in conflict with previous reports for alginate-chitosan nanofilms (Xu et al., 2008): the adsorption of the polyanion described in the literature was achieved with poly(ethylenimine) (PEI) while in the present work we used 1,6-hexanediamine. This possibly affected the aminolyzation degree and hence changed the chemical interactions and binding properties of the outermost layers.

The results in Fig. 3 show that the profile achieved in the successive depositions represent a multilayer film with a moderate hydrophilicity.

\subsubsection{Water vapor permeability (WVP)}

Gas barrier materials play an important role in the packaging of medical supplies and foods, and are used in a wide variety of products (Uemera, 1998). The results from WVP of the A/C PET, polysaccharide multilayer (Alg-Ch-Alg-Ch-Alg) and obtained nanolayered film (A/C PET-Alg-Ch-Alg-Ch-Alg) are presented in Table 1.

The WVP values obtained for the polysaccharide multilayer film are lower than those that could be expected for the materials with which the film was built (i.e. alginate and chitosan

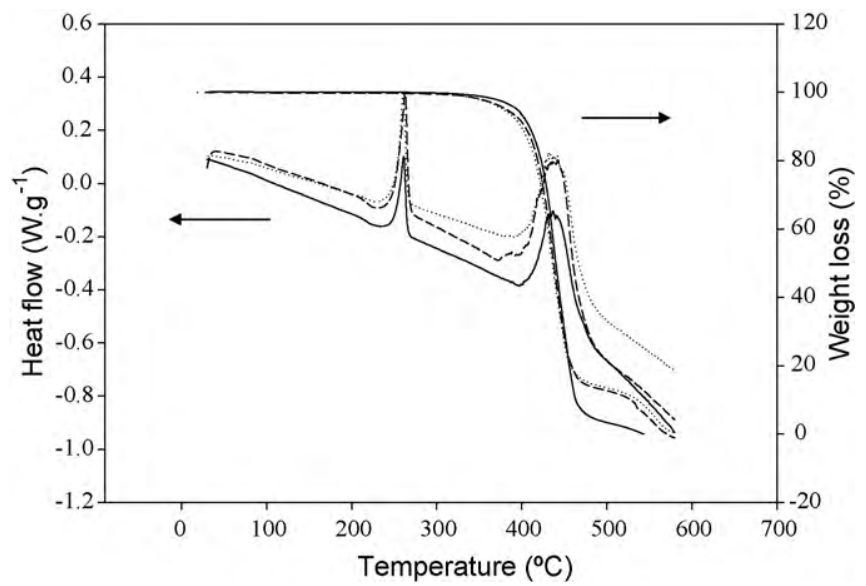

Fig. 4. DSC and TGA curves for: (-) original PET, ( . . A A/C PET, and (-- - ) nanolayered film (each data point is an average of two determinations). 

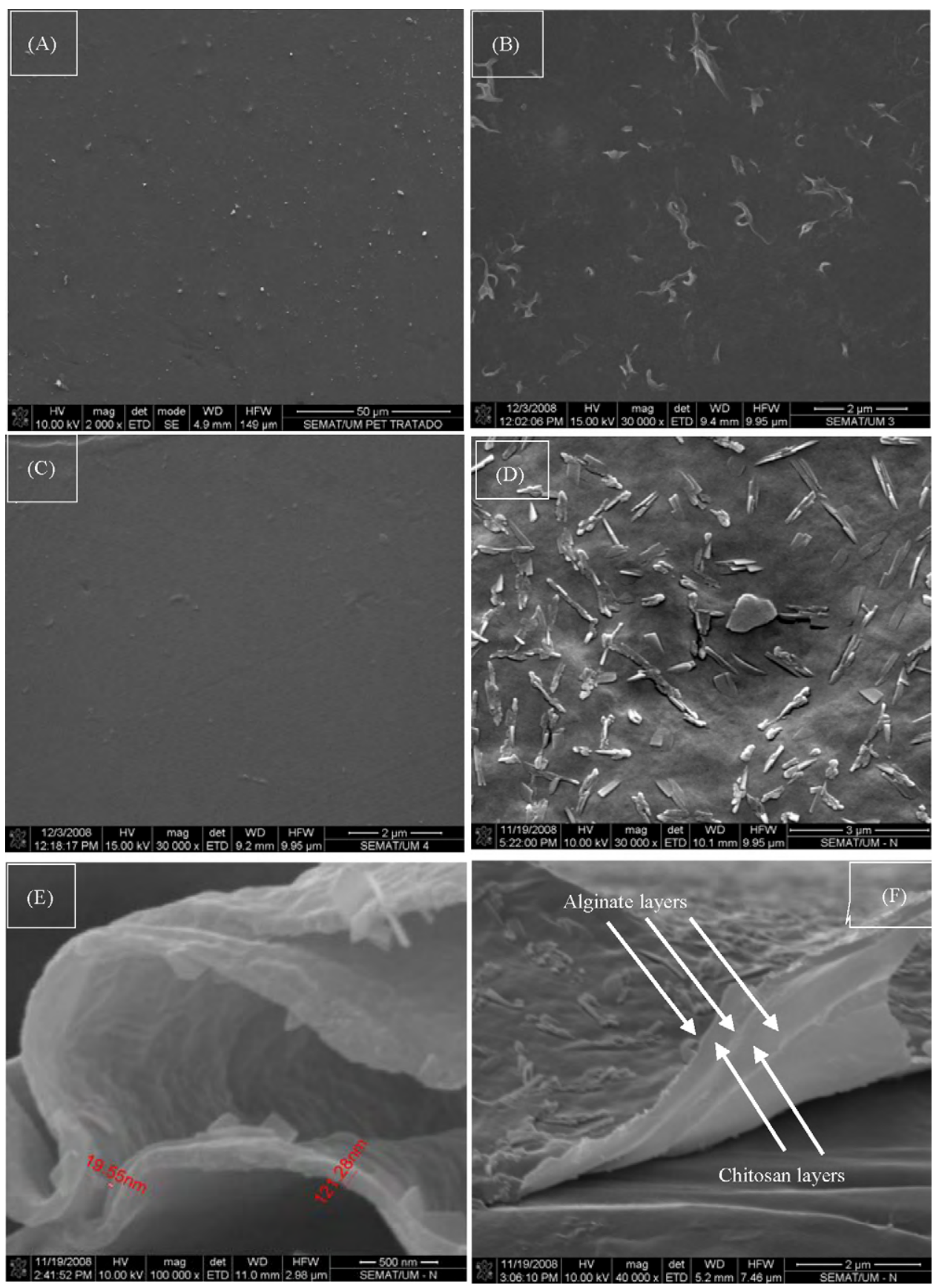

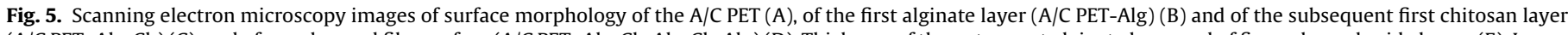

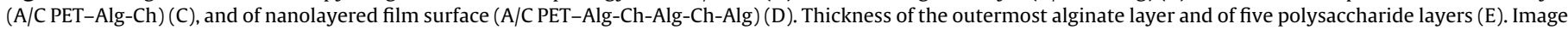
of nanolayered film cross-section $(F)$.

alone). The reported values of alginate and chitosan edible films are $24.6 \times 10^{-11} \mathrm{~g} \mathrm{~m}^{-1} \mathrm{~s}^{-1} \mathrm{~Pa}^{-1}$ (Hambleton et al., 2009) and $3.8 \times 10^{-11} \mathrm{~g} \mathrm{~m}^{-1} \mathrm{~s}^{-1} \mathrm{~Pa}^{-1}$ (Souza et al., 2009), respectively. These good results for the multilayer nanofilm may be explained based on the interactions that are established between adjacent alginate and chitosan layers (Jang et al., 2008; Tieke, Pyrasch, \& Toutianoush, 2002). It may be expected that such interaction increase the tortuosity of the material, thus decreasing its affective permeability to the water molecules (Jang et al., 2008; Tieke et al., 2002). Finally, the presence of a crystalline structure in the fifth layer (see Section 3.2.4) may contribute to the lower WVP values (Jang et al., 2008). As for comparison with multilayer structures, the developed polysaccharide multilayer also presented lower WVP than a bi-layer film of paraffin wax and hydroxypropylmethyl cellulose with polyethy- lene glycol $\left(0.039 \times 10^{-11} \mathrm{~g} \mathrm{~m}^{-1} \mathrm{~s}^{-1} \mathrm{~Pa}^{-1}\right)$ (Pérez-Gago \& Krochta, 2005).

\subsubsection{Thermal analyses}

The effects of the treatment and the addition of the multiple layers of alginate and chitosan on the aminolyzed/charged PET film were also reflected in samples thermal behaviour, which was analyzed by means of differential scanning calorimetry (DSC) and thermogravimetric analysis (TGA).

DSC analyses show (Fig. 4) two peaks above $100^{\circ} \mathrm{C}$ for all samples. The first peak corresponds to the melting temperature $\left(T_{m}\right)$, being the second peak the result of the degradation of the sample. The onset temperature of melting and the melting peak width $\left(\Delta T_{m}\right)$ are related to the heat resistance and to the sample's 
Table 2

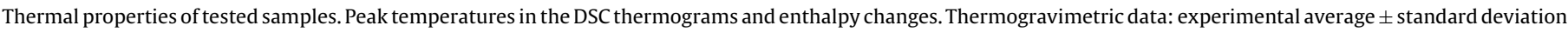

\begin{tabular}{|c|c|c|c|c|c|c|}
\hline Sample & Onset $\left({ }^{\circ} \mathrm{C}\right)$ & $T_{m}\left({ }^{\circ} \mathrm{C}\right)$ & $\Delta T_{m}\left({ }^{\circ} \mathrm{C}\right)$ & $\Delta H_{m}\left(\mathrm{Jg}^{-1}\right)$ & $T_{d i}\left({ }^{\circ} \mathrm{C}\right)$ & $\mathrm{DTG}_{\max }\left({ }^{\circ} \mathrm{C}\right)$ \\
\hline Original PET & $251.88 \pm 2.34$ & $261.31 \pm 0.60$ & 16.29 & $17.25 \pm 0.01$ & $386.0 \pm 2.15$ & $447.3 \pm 4.21$ \\
\hline $\mathrm{A} / \mathrm{C}$ PET & $250.88 \pm 0.01$ & $262.20 \pm 1.52$ & 17.86 & $22.50 \pm 0.05$ & $381.0 \pm 3.01$ & $441.0 \pm 3.59$ \\
\hline Nanolayered film & $250.67 \pm 0.09$ & $262.82 \pm 1.18$ & 18.29 & $31.33 \pm 0.11$ & $330.8 \pm 5.19$ & $433.6 \pm 2.17$ \\
\hline
\end{tabular}

crystallinity, respectively. In general, high melting points are associated with highly regular structures, rigid molecules, close packing capability, strong interchain attraction, or several of these factors combined (Sperling, 2006).

The melting temperatures of the samples are summarized in Table 2, where the value of $T_{m}$ for the original PET was $261.31^{\circ} \mathrm{C}$. This result is in good agreement with the literature (Hatakeyama \& Quinn, 1999; Ke, Long, \& Qi, 1999; Wasikiewicz et al., 2005). PET aminolization and the subsequent addition of the polysaccharide multilayer structure did not considerably affect $T_{m}$.

Greater differences were observed in the enthalpy of melting $\left(\Delta H_{m}\right)$ of the different samples, which can be explained by the structural modification of PET, where the aliphatic group suffers a modification with the addition of the $-\mathrm{N}-$ and $-\mathrm{CH}-$ groups. Table 2 shows an increase of the $\Delta H_{m}$ value while going from the original $\mathrm{PET}$, to the A/C PET and to the nanolayered film. This increase is presumably related with: (i) the higher crystallinity of the modified samples (not directly measured in the present work) and (ii) by the presence of the functional groups added to the original PET: amino groups were added to the A/C PET and amino and carboxylic acid groups were added to the nanolayered films. This last assumption is supported by a reported increase of $\Delta H_{m}$ in PET films incorporated with nanocomposites (Qu et al., 2005), which may affect the thermodynamic properties of the sample in a similar way.

Fig. 4 also shows the TGA curves of the tested samples. The initial decomposition temperature $\left(T_{d i}\right)$ (here considered as the temperature at which the weight loss of the sample is $1 \%$ ) and the derivate maximum decomposing rate temperature $\left(\mathrm{DTG}_{\max }\right.$ ) are also listed in Table 2 . The $T_{d i}$ of the original PET was $386^{\circ} \mathrm{C}$, while the $\mathrm{A} / \mathrm{C}$ PET and nanolayered film present successively lower val-

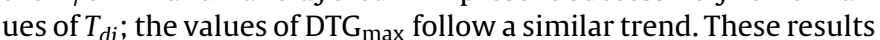
are presumably related with a decrease of the thermal stability of the nanolayered film; this lower thermal stability is certainly related with the presence of alginate and chitosan in the composition of the sample. In fact, the isolated values of $T_{d i}$ for chitosan and sodium alginate ( 293.0 and $225.1^{\circ} \mathrm{C}$, respectively) (Zohuriaan \& Shokrolahi, 2004), can explain the lower value of $T_{d i}$ obtained for that sample.

\subsubsection{Scanning electron microscopy (SEM)}

Fig. 5 shows scanning electron microscopy (SEM) images of different aspects of the tested samples.

The first alginate layer on the A/C PET (Fig. 5B) shows a variety of particle shapes. These shapes appear even shaper in the nanolayered film surface (note that outermost layer is alginate): Fig. 5D, exhibits needle-shaped nano-sized particles, which can be explained by the formation of alginate crystal particules (Cheong \& Zhitomirsky, 2008). This observation is in agreement with the obtained DSC results, which show a higher crystallinity as concluded by the higher $\Delta H_{m}$ values obtained for this case (see Table 2).

The layer of chitosan (Fig. 5C) appears to be smooth, uniform, with a very few nodular shapes. These shapes are most probably, crystals stemming from the preceding alginate layer.

Fig. $5 \mathrm{E}$ is a picture of the nanolayered film, where the thickness of one of the alginate layers could be measured $(19.55 \mathrm{~nm})$, together with the total thickness of the multilayer film $(121.28 \mathrm{~nm})$. One can roughly estimate that the thickness of each chitosan layer is about $[121.28-(19.55 \times 3)] / 2=31.31 \mathrm{~nm}$.

Fig. 5F shows the five layers of the polysaccharides with opposite charges (alginate and chitosan). This SEM picture revealed a greater luminosity of the alginate layers in comparison with that of chitosan layers. This phenomenon is due to the (small) difference between the measured electrical conductivity of alginate $\left(1.40 \pm 0.02 \mathrm{mS} \mathrm{cm}^{-1}\right)$ and that of chitosan $\left(1.47 \pm 0.01 \mathrm{mS} \mathrm{cm}^{-1}\right)$, which renders alginate to be the first to become electrically charged after the incidence of the electron beam during SEM analysis.

\subsubsection{Nanoindentation experiments}

The hardness of the A/C PET and of the nanolayered film alone was measured. Using the $\mathrm{A} / \mathrm{C}$ PET as a reference, the presence of the multilayer represented a hardness increase of $0.245 \pm 0.06 \mathrm{GPa}$, which corresponds to an increase of $18.3 \%$ of the hardness. These values are of the same order of magnitude of the reported values for chitosan coatings with different concentrations of montmorillonite and different treatments, that present hardness increase ranging from 0.110 to $0.199 \mathrm{GPa}$ (Martin, Schulz, Bumgardner, \& Schneider, 2008). In our case, values are higher, presumably due to the presence of the multiple layers of alginate/chitosan, which help dissipating the crack tip energy, thus improving the hardness of the material (Carvalho et al., 2004; Tromas et al., 2007).

\section{Conclusions}

Chitosan and sodium alginate with opposite charges were adsorbed onto aminolyzed/charged films of polyethylene terephthalate, through layer-by-layer assembly. Differences in the contact angle measurements were found for the films with a successively higher number of layers. The five layers were observed through SEM images, which allowed the measurement of the layer thickness. The nanolayered film presented a WVP of $(0.85 \pm 0.04) \times 10^{-11} \mathrm{~g} \mathrm{~m}^{-1} \mathrm{~s}^{-1} \mathrm{~Pa}^{-1}$ and a hardness increase of $0.245 \pm 0.06 \mathrm{GPa}$. The thermal properties of this structure were assessed by differential scanning calorimetry and thermogravimetric analysis, showing increases of $39.2 \%$ of the melting energy when compared with the A/C PET film, and a decrease of $15.2 \%$ of the decomposition temperature.

This work has shown that nanolaminates present highly functional properties and promising future applications onto different types of substrates aiming at e.g. the preparation of multilayer films coating biomedical appliances or multilayer edible coatings with enhanced mass transfer and mechanical properties.

\section{Acknowledgements}

M.A. Cerqueira was recipient of a fellowship from the Fundação para a Ciência e Tecnologia (FCT, Portugal) through grant SFRH/BD/23897/2005; B.W.S. Souza was recipient of a fellowship from the Coordenação de Aperfeiçoamento de Pessoal de Nível Superior (CAPES, Brazil); financial support from CAPES/Procad/1415/2007 is also gratefully acknowledged. We also acknowledge Dr. Edith Ariza from SEMAT/UM by the support in SEM and EDS analysis. 


\section{References}

Abu-Sharkh, B. (2006). Structure and mechanism of the deposition of multilayers of polyelectrolytes and nanoparticles. Langmuir, 22(7), 3028-3034.

Antunes, J. M., Cavaleiro, A., Menezes, F., Simões, M. I., \& Fernandes, J. V. (2002). Ultramicrohardness testing procedure with Vickers indenter. Surface and Coatings Technology, 149, 27-35.

Carvalho, S., Ribeiro, E., Rebouta, L., Tavares, C., Mendonça, J. P., Monteiro, A. C., Carvalho, N. J. M., De Hosson, J. Th. M., \& Cavaleiro, A. (2004). Microstructure, mechanical properties and cutting performance of superhard ( $\mathrm{Ti}, \mathrm{Si}, \mathrm{Al}) \mathrm{N}$ nanocomposite films grown by d. c. reactive magnetron sputtering. Surface and Coatings Technology, 177-178, 459-468.

Casariego, A., Souza, B. W. S., Cerqueira, M. A., Teixeira, J. A., Cruz, L., Díaz, R., \& Vicente, A. A. (2009). Chitosan/clay films' properties as affected by biopolymer and clay micro/nanoparticles' concentrations. Food Hydrocolloids, 23, 1895-1902.

Cerqueira, M. A., Lima, A. M., Souza, B. W. S., Teixeira, J. A., Moreira, R. A., \& Vicente, A. A. (2009). Functional polysaccharides as edible coatings for cheese. Journal of Agricultural and Food Chemistry, 57, 1456-1462.

Cheong, M., \& Zhitomirsky, I. (2008). Electrodeposition of alginic acid and composite films. Colloids and Surfaces A, 328, 73-78.

Cooksey, K., Marsh, K. S., \& Doar, L. H. (1999). Predicting permeability \& transmission rate for multilayer materials. Food Technology, 53(9), 60-63.

Decher, G., \& Schlenoff, J. B. (Eds.). (2002). Sequential assembly of nanocomposite material multilayer thin films. (pp. 1-31). Wiley-VCH Verlag GmbH \& Co. KGaA.

Dowling, D. P., Kola, P. V., Donnelly, K., Kelly, T. C., Brumitt, K., Lloyd, L., Eloy, R., Therin, M., \& Weill, N. (1997). Evaluation of diamond-like carbon-coated orthopaedic implants. Diamond and Related Materials, 6, 390-393.

Dronov, R., Kurth, D. G., Möhwald, H., Scheller, F. W., Friedmann, J., Pum, D., Sleytr, U. B., \& Lisdat, F. (2008). Self-assembly of S-layer-enveloped cytochrome c polyelectrolyte multilayers. Langmuir, 24(16), 8779-8784.

Fávaro, S. L., Rubira, A. F., Muniz, E. C., \& Radovanovic, E. (2007). Surface modification of HDPE, PP, and PET films with $\mathrm{KMnO}_{4} / \mathrm{HCl}$ solutions. Polymer Degradation and Stability, 92, 1219-1226.

Fu, J., Ji, J., Yuan, W., \& Shen, J. (2005). Construction of anti-adhesive and antibacterial multilayer films via layer-by-layer assembly of heparin and chitosan. Biomaterials, 26, 6684-6692.

Guillard, V., Broyart, B., Bonazzi, C., Guilbert, S., \& Gontard, N. (2003). Preventing moisture transfer in a composite food using edible films: Experimental and mathematical study. Journal of Food Science, 68(7), 2267-2277.

Hambleton, A., Frédéric Debeaufort, F., Bonnotte, A., \& Voilley, A. (2009). Influence of alginate emulsion-based films structure on its barrier properties and on the protection of microencapsulated aroma compound. Food Hydrocolloids, 23(8), 2116-2124.

Hatakeyama, T., \& Quinn, F. X. (1999). Application of thermal analysis. In Thermal analysis fundamentals and applications to polymer science. John Wiley \& Sons Ltd.

Jang, W.-S., Rawson, I., \& Grunlan, J. C. (2008). Layer-by-layer assembly of thin film oxygen barrier. Thin Solid Films, 516, 4819-4825.

Ke, Y., Long, C., \& Qi, Z. (1999). Crystallization, properties, and crystal and nanoscale morphology of PET-clay nanocomposites. Journal of Applied Polymer Science, 71, 1139-1146.

Kujawa, P., Schmauch, G., Viitala, T., Badia, A., \& Winnik, F. M. (2007). Construction of viscoelastic biocompatible films via the layer-by-layer assembly of hyaluronan and phosphorylcholine-modified chitosan. Biomacromolecules, 8, 3169-3176.

Kumar, R. M. N. V., Muzzarelli, R. A. A., Muzzarelli, C., Sashiwa, H., \& Domb, A. J. (2004). Chitosan chemistry and pharmaceutical perspectives. Chemical Reviews, 104, 6017-6084.

Lin, M.-C., Chang, L.-S., \& Lin, H. C. (2008). Gas barrier properties of titanium oxynitride films deposited on polyethylene terephthalate substrates by reactive magnetron sputtering. Applied Surface Science, 254, 3509-3516.

Lukkari, J., Salomki, M., Ritalo, T., Loikas, K., Laiho, T., \& Kankare, J. (2002). Preparation of multilayers containing conjugated thiophene-based polyelectrolytes. Layerby-layer assembly and viscoelastic properties. Langmuir, 18, 8496-8502.

Martin, H. J., Schulz, K. H., Bumgardner, J. D., \& Schneider, J. A. (2008). Enhanced bonding of chitosan to implant quality titanium via four treatment combinations. Thin Solid Films, 516, 6277-6286.

McHugh, T. H., Avena-Bustillos, R. J., \& Krochta, J. M. (1993). Hydrophilic edible film: Modified procedure for water vapor permeability and explanation of thickness effects. Journal Food Science, 58(4), 899-903.

Newman, A. W., \& Kwok, D. Y. (1999). Contact angle measurement and contact angle interpretation. Advances in Colloid and Interface Science, 81(3), 167-249.

Olivas, G. I., \& Barbosa-Cánovas, G. V. (2008). Alginate-calcium films: Water vapor permeability and mechanical properties as affected by plasticizer and relative humidity. LWT Food Science and Technology, 41(2), 359-366.
Oliver, W. C., \& Pharr, G. M. (1992). An improved technique for determining hardness and elastic modulus using load and displacement sensing indentation experiments. Journal of Materials Research, 7, 1564-1583.

Pérez-Gago, M. B., \& Krochta, J. M. (2005). Emulsion and bi-layer edible films. In Han Jung (Ed.), Innovations in food packaging (2nd edition, pp. 108-122). Elsevier Science \& Technology Books.

Qu, M., Wang, Y., Wang, C., Ge, X., Wang, D., \& Zhou, Q. (2005). A novel method for preparing poly(ethylene terephthalate) $/ \mathrm{BaSO}_{4}$ nanocomposites. European Polymer Journal, 41, 2569-2574.

Raybaudi-Massilia, R. M., Mosqueda-Melgar, J., \& Martín-Belloso, O. (2008). Edible alginate-based coating as carrier of antimicrobials to improve shelf-life and safety of fresh-cut melon. International Journal of Food Microbiology, 121, 313-327.

Ribeiro, C., Vicente, A. A., Teixeira, J. A., \& Miranda, C. (2007). Optimization of edible coating composition to retard strawberry fruit senescence. Postharvest Biology and Technology, 44, 63-70.

Rojas-Graü, M. A., Tapia, M. S., \& Martín-Belloso, O. (2008). Using polysaccharidebased edible coatings to maintain quality of fresh-cut Fuji apples. LWT Food Science and Technology, 41(1), 139-147.

Rudra, J. S., Dave, K., \& Hayne, D. T. (2006). Antimicrobial polypeptide multilayer nanocoatings. Journal of Biomaterial Science Polymer Edition, 17(11), 13011315.

Santos, D. S., Jr., Riul, A., Jr., Malmegrim, R. R., Fonseca, F. J., Oliveira, O. N., Jr., \& Mattoso, L. H. C. (2003). A layer-by-layer film of chitosan in a taste sensor application. Macromolecular Bioscience, 3, 591-595.

Shogren, R. (1997). Water vapor permeability of biodegradable polymers. Journal of Environmental Polymer Degradation, 5(2), 1997.

Sionkowska, A. (2006). Effects of solar radiation on collagen and chitosan films. Journal of Photochemistry and Photobiology B: Biology, 82, 9-15.

Souza, B. W. S., Cerqueira, M. A., Casariego, A., Lima, A. M. P., Teixeira, J. A., \& Vicente, A. A. (2009). Effect of moderate electric fields in the permeation properties of chitosan coatings. Food Hydrocolloids, 23, 2110-2115.

Sperling, L. H. (Ed.). (2006). Introduction to physical polymer science (p. 239). New Jersey: John Wiley \& Sons, Inc.

Strand, S. P., TØmmeraas, K., Värum, K. M., \& Østgaard, K. (2001). Electrophoretic light scattering studies of chitosans with different degrees of $\mathrm{N}$-acetylation. Biomacromolecules, 2, 1310-1314.

Sutton, A., Harrison, B. E., Carr, T. E., \& Barltrop, D. (1971). Reduction in the absorption of dietary strontium in children by an alginate derivative. International Journal of Radiation Biology, 19, 79-85.

Tapia, M. S., Rojas-Graü, M. A., Carmona, A., Rodríguez, F. J., Soliva-Fortuny, R., \& Martin-Belloso, O. (2008). Use of alginate- and gellan-based coatings for improving barrier, texture and nutritional properties of fresh-cut papaya. Food Hydrocolloids, 22(8), 1493-1503.

Tieke, B., Pyrasch, M., \& Toutianoush, A. (2002). In G. Decher, \& J. B. Schlenoff (Eds.), Multilayer thin films: Sequential assembly of nanocomposite materials (4th edition, pp. 427-458). Wiley-VCH Verlag GmbH \& Co. KGaA.

Tromas, C., Verdier, M., Fivel, M., Aubert, P., Labdi, S., Feng, Z. Q., Zei, M., \& Joli, P. (2007). In C. Bréchignac, P. Houdy, \& Lahmani M (Eds.), Nanomaterials and nanochemistry (pp. 229-267). Berlin Heidelberg: Springer-Verlag.

Uemera, E. (1998). New development in functional packaging materials. Toray Research Centre Report (p. 159).

Vargas, M., Albors, A., Chiralt, A., \& González-Martínez, C. (2009). Characterization of chitosan-oleic acid composite films. Food Hydrocolloids, 23(2), 536547.

Wasikiewicz, J. M., Yoshii, F., Nagasawa, N., Wach, R. A., \& Mitomo, H. (2005). Degradation of chitosan and alginate by gamma radiation, sonochemical and ultraviolet methods. Radiation Physics and Chemistry, 73, 287-295.

Weiss, J., Takhistov, P., \& McClements, D. J. (2006). Functional materials in food nanotechnology. Journal of Food Science, r107-r116.

Xu, J.-P., Wang, X.-L., Fan, De-Z., Ji, J., \& Shen, J.-C. (2008). Construction of phospholipid anti-biofouling multilayer on biomedical PET surfaces. Applied Surface Science, 255, 538-540.

Yoo, D., Shiratori, S. S., \& Rubner, M. F. (1998). Controlling bilayer composition and surface wettability of sequentially adsorbed multilayers of weak polyelectrolytes. Macromolecules, 31, 4309-4318.

Zhong, Y., Li, B., \& Haynie, D. T. (2006). Control and stability of polypeptide multilayer nanofilms by quantitative control of disulfite bond formation. Nanotechnology, 17, 5726-5734.

Zhu, Y., Gao, C., He, T., \& Shen, J. (2004). Endothelium regeneration on luminal surface of polyurethane vascular scaffold modified with diamine and covalently grafted with gelation. Biomaterials, 25, 423-430.

Zohuriaan, M. J., \& Shokrolahi, F. (2004). Thermal studies on natural and modified gums. Polymer Testing, 23, 575-579. 